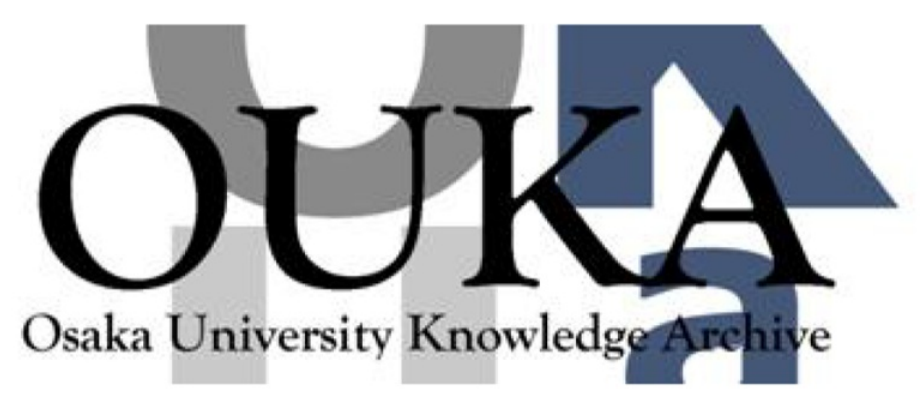

\begin{tabular}{|c|c|}
\hline Title & $\begin{array}{l}\text { Electrical and optical properties of conducting } \\
\text { polymer in liquids }\end{array}$ \\
\hline Author (s) & Yoshino, K.; Inoue, M.; Yoshida, Y. et al. \\
\hline Citation & $\begin{array}{l}\text { IEEE International Conference on Conduction and } \\
\text { Breakdown in Dielectric Liquids, ICDL. p. 390- } \\
\text { p. } 392\end{array}$ \\
\hline Issue Date & $2002-07$ \\
\hline oaire:version & VoR \\
\hline URL & https://hdl. handle. net/11094/14063 \\
\hline rights & $\begin{array}{l}\text { c2002 IEEE. Personal use of this material is } \\
\text { permitted. However, permission to } \\
\text { reprint/republish this material for advertising } \\
\text { or promotional purposes or for creating new } \\
\text { collective works for resale or redistribution } \\
\text { to servers or lists, or to reuse any } \\
\text { copyrighted component of this work in other } \\
\text { works must be obtained from the IEEE. }\end{array}$ \\
\hline Note & \\
\hline
\end{tabular}

Osaka University Knowledge Archive : OUKA

https://ir. Library. osaka-u. ac. jp/

0saka University 


\title{
Electrical and Optical Properties of Conducting Polymer in Liquids
}

\author{
Yoshino K., Inoue M., Yoshida Y. Ootake R., Nishihara Y., Fujii A., Ozaki M., Moritake H.*, Toda K.* \\ Department of Electronic Engineering Graduate School of Engineering \\ Osaka University 2-1 Yamada-oka, Suita, Osaka 565-0871, JAPAN \\ *Department of Electronic Engineering, National Defense Academy, \\ 1-20-20, Hashirimizu, Yokosuka, Kanagawa 239-8686, JAPAN
}

\begin{abstract}
Electrical properties such as electrical conductivity and dielectric property, optical properties such as photoconductivity and photoluminescence and mechanical properties such as viscosity of conducting polymers such as polythiophene, poly( $p$-pennylenevinylene) and polyacetylene derivatives in liquids, that is, in solution and fused liquid state have been studied as functions of molecular structure and temperature. These properties in these substituted derivatives, were dependent on the substituent strongly, and charged drastically at the melting point, which have been discussed by taking the conformation of the substituents and inter polymer main chain interactions into consideration. Electrorheological effect in conducting polymer solution has also been studied and was found to be dependent both molecular structures and temperature, which can be also interpreted in terms molecular reorientation and changes of molecular conformation and interchain interaction.
\end{abstract}

\section{INTRODUCTION}

Conducting polymers with highly extended $\pi$-electron system in their main chains have attracted much interest from both fundamental and practical view points. However, they were considered to be nonfusible and insoluble, which restricted their practical applications. We have found that by the introduction of long side chains as substituents, a conducting polymer such as poly(3-alkylthiophene) becomes fusible at relatively low temperature and also soluble in common solvents. Because these liquid conducting polymers have much smaller band gaps than those of conventional organic liquids and molten polymers, they exhibit relatively high electrical conductivity which originates in electronic transport and cause interesting interactions with visible light. We have reported novel electrical and optical properties in these liquid conducting polymers. In this paper we have studied electrical, optical and mechanical properties of conducting polymers in liquids as function of substituents, temperature, applied electric field and optical radiation. Especially a study of electrorheological effect conducting polymer liquids has been focused utilizing ultrasonic surface acoustic wave.

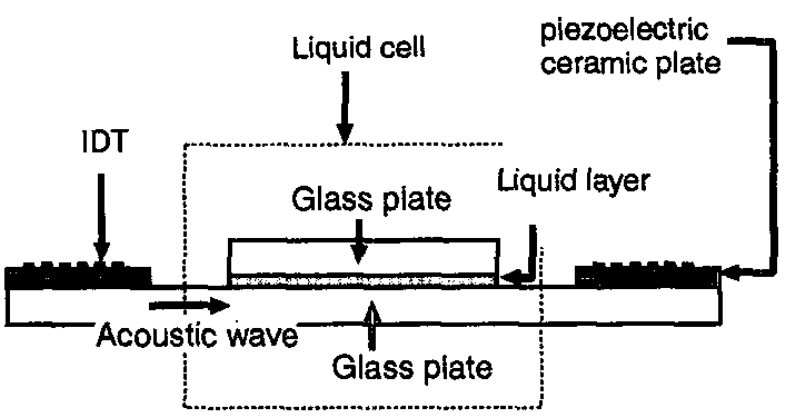

Fig.1. Schematic construction of device.

\section{EXPERIMENTAL RESULTS}

Figure 1 shows a schematic construction of an acoustic wave device including the liquid cell prepared for the experimental study. Two interdigital transducers (IDTs) are mounted on a $230 \mu \mathrm{m}$-thick piezoelectric ceramic plate (TDK, 101A) cemented on one of the two glass plates. Each of the IDTs has an interdigital periodicity of $400 \mu \mathrm{m}$ and seven electrode-finger pairs. A liquid layer, located at the central position of the acoustic wave device, is sandwiched between two $400 \mu \mathrm{m}$-thick glass plates (Corning, 7059) coated with In-Sn oxide (ITO) thin film. The thickness of the liquid layer is $25 \mu \mathrm{m}$, adjusted by a polyethyleneterephythalate (PET) film as the spacer. The tested sample, poly(3alkylthiophene), is dissolved in various solvents such as anisole and toluene, and the concentration is $0.001 \mathrm{~g} / \mathrm{ml}$. The acoustic wave is excited in the part of the IDT, and then detected as a delayed electrical signal at the other IDT after propagating in the liquid cell region. The acoustic phase-delay and the propagation loss between the two IDTs are measured by a network analyzer (HP, 4195A). A dc electric field is applied to the liquid layer in the direction parallel to the thickness of the liquid cell. The acoustic phase delay and propagation loss are measured by with and without application of electric field. 


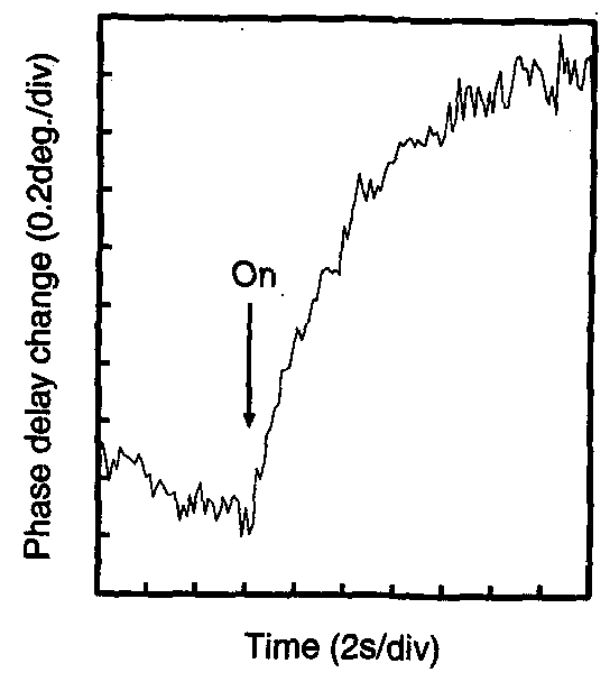

Fig.2. Dynamic response of phase delay change.

The acoustic phase-delay change is related to the phase velocity of the acoustic wave. The phase velocity change of the acoustic wave is induced by the change of the some properties of the liquid, such as viscosity [1]. As the result, the acoustic phasedelay change in the experiment related to the change of the liquid viscosity.

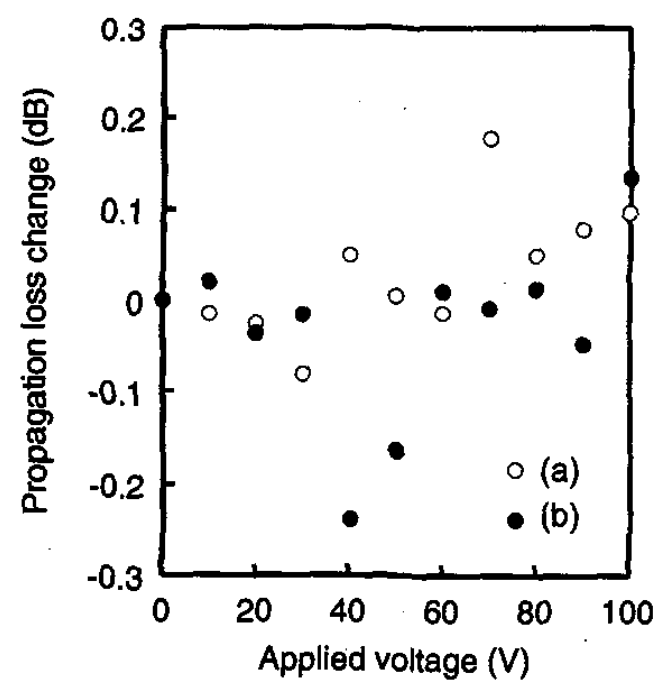

Fig.3. Applied voltage dependence of propagation loss change. (a) Solution of poly(3-alkylthiophene) in anisole (b) pure anisole solvent.
Figure 2 shows the dynamic response of the acoustic phase delay measured under applying voltage of $100 \mathrm{~V}$. The electric field is applied to the liquid cell. The acoustic phase delay changes under the application of electric field. The poly(3-alkylthiophene) forms a rodlike structure in the anisole solvent [2]. The acoustic phasedelay change is considered to be induced by the interaction between the electric voltage and the dipole moment of poly(3alkylthiophene) in anisole. However, the gradually increase of the acoustic phase delay might be related to the relaxation process of the acoustic wave.

Figure 3 shows the applied voltage dependences of the acoustic phase-delay change. Open and closed circles denote the solution of poly(3-alkylthiophene) in anisole (a) and the pure anisole solvent (b). The relationship between the propagation loss of the acoustic wave and the applied voltage to the liquid cell is not observed in this experimental result.

Measured applied voltage dependences of the acoustic phasedelay change are shown in Fig. 4. No electrorheological characteristics are observed in the case of the pure anisole solvent, the clear voltage dependence of the viscosity of the anisole solution of poly(3-alkylthiophene) is attributed to some effects of the conducting polymer.

Figure 5 shows the applied voltage dependence of the acoustic phase-delay change in the cases of (a) poly(3-alkylthiophene) in toluene and (b) pure toluene solvent. The relationship between

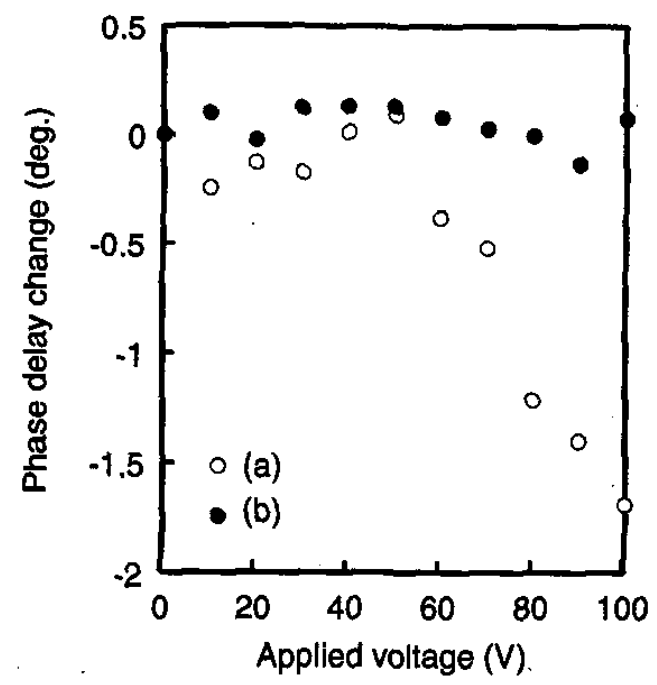

Fig.4. Applied voltage dependence of acoustic phase delay change. (a) Solution of poly (3-alkylthiophene) in anisole (b) pure anisole solvent. 


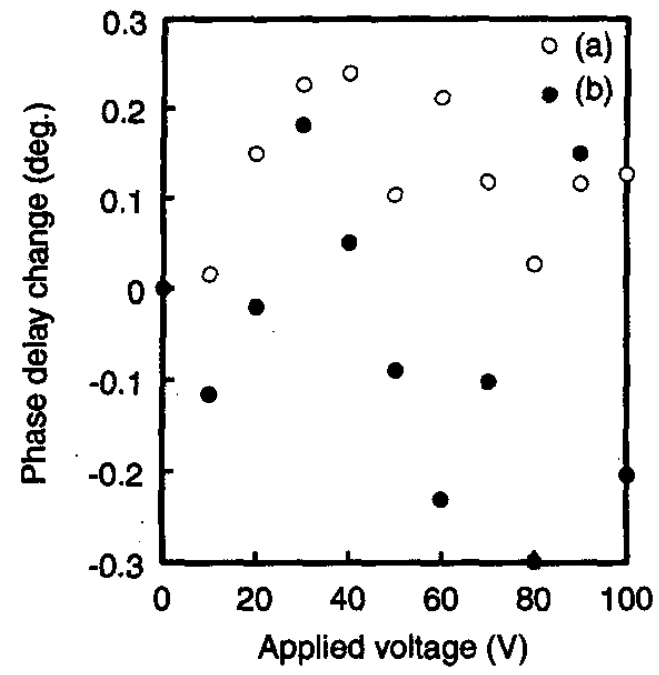

Fig.5. Applied voltage dependence of acoustic phase delay change. (a) Solution of poly(3-alkylthiophene) in toluene (b) pure toluene solvent.

the acoustic phase-delay change and the applied voltage to the liquid cell is not observed.

Figure 6 shows the applied voltage dependence of the acoustic phase-delay change. Open and closed circles denote the solution of poly(3-alkylthiophene) in (a) anisole and (b) toluene, respectively. The acoustic phase-delay change decrease with increasing applying voltage in the case (a). On the other hand, it is hardly observed in the case of (b). The decrease of the acoustic phase-delay change corresponds to the increase of the viscosity. The different electrorheological properties are shown when the poly (3-alkylthiophene) is dissolved in various solvents.

\section{SUMMARY}

By the observation of the interaction of the surface acoustic wave with conducting polymer in liquids electrorheological effect of conducting polymer in liquids was studied. Acoustic phase delay and attenuation are found to be dependent on applied voltage in poly (3-octadecylthiopehené) in anisole but not in toluene. The optical properties such as absorption spectra of poly(3alkylthiophene) also different in both liquids. These electroreological and optical properties can be explained by taking the difference of molecular conformation in different liquids into consideration.

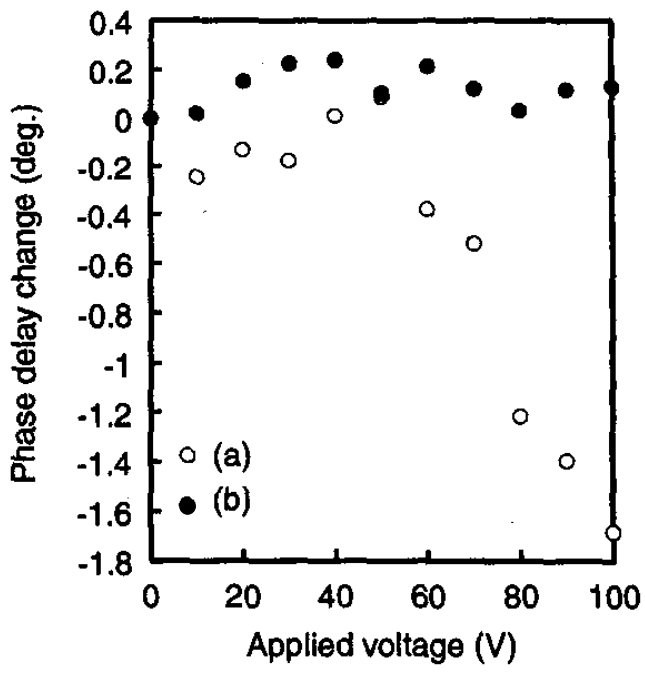

Fig.6. Applied voltage dependence of acoustic phase delay change. Solution of poly(3-alkylthiophene) in (a) anisole and (b) toluene.

\section{REFERENCES}

[1] Inoue M., Yoshino K., Moritake H. and Toda K. "Observation of Orientation Dependence of Electrorheology Effect in Ferroelectric Liquid Crystal Using Shear Horizontal Wave", Appl. Phys. Lett. Vol. 79. No. 26, 24 December 2001, pp. 4345-4347.

[2] Yoshino K., Morita S., Yin X. H. and Kawai T. "Optical and Rheological Properties of Poly(3-alkylthiophene) Solution", Jpn. J. Appl. Phys. Vol. 32. No. 4A, 1 April 1993, pp. L547L549. 